\title{
Expression and possible involvement of calpain isoforms in mammalian egg activation
}

\author{
Irit Ben-Aharon ${ }^{1}$, Karin Haim ${ }^{1}$, Ruth Shalgi ${ }^{1}$ and Dalit Ben-Yosef ${ }^{2}$ \\ ${ }^{1}$ Department of Cell and Developmental Biology, Sackler Faculty of Medicine, Tel Aviv University, Tel-Aviv, Israel \\ and ${ }^{2}$ Sara Racine IVF Unit, Tel Aviv Sourasky Medical Center, Tel Aviv, Israel
}

Correspondence should be addressed to D Ben-Yosef, Sara Racine IVF Unit, Lis Maternity Hospital, Tel Aviv Sourasky Medical Center, 6 Weizmann Street, Tel Aviv 64239, Israel; Email: dalitb@tasmc.health.gov.il)

\begin{abstract}
At fertilization in mammals, the spermatozoon triggers a unique signal transduction mechanism within the egg, leading to its activation. It is well accepted that the earliest event observed in all activated eggs is an abrupt rise in intracellular calcium concentrations. However, little is known regarding the downstream proteins that are activated by this rise in calcium. Calpains constitute a family of intracellular calcium-dependent cysteine proteases whose members are expressed widely in a variety of cells. We investigated the expression and possible role of the calpain isoforms $\mu$ and $\mathrm{m}$ throughout egg activation. Both calpains were expressed in the rat egg and localized at the egg cortex as well as in the meiotic spindle. $m$ Calpain translocated to the membrane and to the spindle area during parthenogenetic egg activation and during in vivo fertilization, upon sperm binding to the egg. The cytoskeletal protein $\alpha$-spectrin (fodrin) was proteolysed by calpain during the egg-activation process, as demonstrated by specific calpain-breakdown products. Following parthenogenetic activation by ionomycin or puromycin, the calpain-selective permeable inhibitor, calpeptin, inhibited the resumption of meiosis and cortical reaction in a dosedependent manner. Calpeptin was also effective in inhibiting in vitro fertilization. These results may imply a correlation between calpain activation and mammalian egg activation at fertilization and a possible role for calpain in the cascade of cellular events leading to resumption of meiosis.

Reproduction (2005) 130 165-175
\end{abstract}

\section{Introduction}

At fertilization in mammals, the spermatozoon triggers a unique signal transduction mechanism within the egg, leading to its activation towards the development of an embryo. The foremost event observed in all activated mammalian eggs is an abrupt rise in intracellular calcium concentrations $\left(\left[\mathrm{Ca}^{2+}\right]_{i}\right)$ followed by a series of $\left[\mathrm{Ca}^{2+}\right]_{i}$ oscillations (Miyazaki et al. 1993, Lawrence et al. 1994). Thus, the increase in $\left[\mathrm{Ca}^{2+}\right]_{i}$ plays a pivotal role in the activation process, where it mediates the characteristic cellular events of egg activation, the earliest of which is exocytosis of the contents of the cortical granules, or the so-called cortical reaction (CR). The CR leads to modification of the zona pellucida and hence to the blocking of polyspermy (Ducibella et al. 1994, Raz \& Shalgi 1998). Later events include resumption of meiosis and extrusion of the second polar body, decondensation of the sperm head, maternal RNA recruitment, formation of paternal and maternal pronuclei, initiation of DNA synthesis and mitotic cleavages.
Induction of a single $\left[\mathrm{Ca}^{2+}\right]_{\mathrm{i}}$ rise by exposure of eggs arrested at the second meiotic division (MII eggs) to a $\mathrm{Ca}^{2+}$ ionophore leads to both $\mathrm{CR}$ and resumption of meiosis, whereas employing $\mathrm{Ca}^{2+}$ chelators inhibits these events (Jaffe 1983, Kline \& Kline 1992, Tombes et al. 1992, Vincent et al. 1992, Ducibella et al. 1994, Raz \& Shalgi 1998, Ducibella et al. 2002). However, it has been suggested that the $\left[\mathrm{Ca}^{2+}\right]_{i}$ oscillations are required for early embryonic development. Little is known regarding the cellular pathways by which calcium exerts its signal during egg activation. Recently, a role had been suggested for proteins such as $\mathrm{Ca}^{2+} /$ calmodulin-dependent protein kinase II (CaMKII) and calmodulin in mediating the signal required for resumption of meiosis (Tatone et al. 2002, Markoulaki et al. 2003).

Calpains constitute a family of intracellular calciumdependent cysteine proteases whose members are expressed widely in a variety of tissues and cells (Murachi 1989, Sorimachi et al. 1995, Carafoli \& Molinari 1998). Two ubiquitous members of the calpain family, the $\mu$ and $\mathrm{m}$ isoforms, have been well characterized in many cells. 
They are both heterodimers, comprised of a large catalytic subunit of $80 \mathrm{kDa}$ and a small regulatory subunit of $30 \mathrm{kDa}$. However, they differ considerably in the calcium concentrations that they require for their activation in vitro. $\mu$ Calpain is activated at micromolar calcium concentrations and $\mathrm{m}$ calpain at millimolar concentrations (Croall \& DeMartino 1991, Sorimachi et al. 1995). Calpains are pluripotential proteases that have been implicated in diverse cellular signaling pathways mediated by calcium, such as cytoskeleton remodeling, cell-cycle regulation, cell differentiation and apoptosis (Carafoli \& Molinari 1998, Croall \& DeMartino 1991). It had been suggested that calpain is associated with the chromosomes and with the spindle region during mitosis (Schollmeyer 1988, Lane et al. 1992). Calpain was also considered to participate in microtubule assembly and disassembly (Billger et al. 1988, 1993).

The dominant rise in $\left[\mathrm{Ca}^{2+}\right]_{i}$ following fertilization may also imply calpain involvement during re-initiation of meiosis. Injection of calpain into the nuclei of prophasearrested starfish oocytes induced re-initiation of meiosis, reflected by germinal vesicle breakdown, as occurs in oocyte maturation (Santella et al. 1998). Thus, calpain may participate in the breakdown of cytoskeletal protein during the disassembly of the nuclear envelope (Santella et al. 2000). In MII-arrested Xenopus eggs, calpain might play a role in meiosis regulation by inactivating the c-mos protooncogene product, $\mathrm{pp}^{39}$, thus leading to resumption of the second meiosis (Watanabe et al. 1989, Sagata et al. 1989). However, this theory has been controversial since it has been implied that calpain is capable of degrading the cmos product only in vitro, at supraphysiological calcium concentrations (Lorca et al. 1991). In an earlier study, we demonstrated calpain expression in rat eggs (Malcov et al. 1997). We have recently displayed the expression of the calpain-calpastatin system in human oocytes as well (Ben-Aharon et al. 2005).

In our present study, we focused on the calpain isoforms $\mu$ and $\mathrm{m}$, and demonstrated their expression and localization in the rat egg throughout egg activation. We further examined the role of calpain in egg activation during in vitro fertilization and during parthenogenetic activation by a calcium ionophore.

The appearance of breakdown products of $\alpha$-spectrin (fodrin), a known substrate of calpain, following egg activation served as a marker for calpain activation. In order to explore a possible role for calpain in mammalian egg activation, we introduced either one of calpain inhibitors, calpeptin or calpain inhibitor III (MDL28170), to MII eggs and then activated them. Inhibition of resumption of meiosis was detected in a dose-dependent manner. Inhibition of cortical granule exocytosis was also detected to a lesser extent.

\section{Materials and Methods}

All studies were carried out according to an approved protocol as dictated in Tel Aviv University guidelines of the institutional animal care and use committee.

\section{Collection of eggs}

\section{MIl eggs}

For ovulation induction, 23-26-day-old immature Wistarderived female rats were injected with $10 \mathrm{IU}$ human chorionic gonadotropin (hCG; Sigma, St Louis, MO, USA) $48-54 \mathrm{~h}$ after administration of $10 \mathrm{IU}$ pregnant mares' serum gonadotropin (Syncro-part, Sanofi, France). Rats were killed $14 \mathrm{~h}$ after hCG administration. Cumulusenclosed MII eggs were isolated from the oviductal ampullae in Toyoda Hepes (TH) medium (Ben-Yosef et al. 1995) supplemented with $0.4 \%$ BSA (for immunofluorescence) or $0.1 \%$ BSA (for immunoblotting). Cumulus cells were removed by a brief exposure to $400 \mathrm{IU} / \mathrm{ml}$ highly purified hyaluronidase ( $\mathrm{H}-3631$; Sigma) in $\mathrm{TH}$ medium. The temperature of the medium was kept at $37^{\circ} \mathrm{C}$ for all experiments.

\section{Fertilized eggs}

Immature female rats were allowed to mate after an injection of hCG with males of proven fertility. The females were killed $15 \mathrm{~h}$ after hCG administration. Eggs were isolated from the oviductal ampullae at different stages of fertilization, as described for the hamster (Eliyahu \& Shalgi 2002). Only early stages of fertilization were assessed for the experiments: sperm binding, $0-15 \mathrm{~min}$ after sperm attachment; fertilization cone, 15-60 min after sperm attachment.

\section{Parthenogenetic activation}

MII ovulated eggs were activated parthenogenetically in the dark by $2 \mu \mathrm{M}$ calcium ionophore (ionomycin; Calbiochem, San Diego, CA, USA) for 3-5 min followed by an additional 0 or 20 min of incubation in fresh TH medium lacking the activator. We also looked at egg activation by $20 \mu \mathrm{M}$ puromycin (Sigma) for $3 \mathrm{~h}$.

\section{Immunofluorescence staining and laser-scanning confocal microscopy}

Eggs at the appropriate developmental stages were fixed for $10 \mathrm{~min}$ at room temperature in 3\% paraformaldehyde (Merck, Gibbstown, NJ, USA) in Dulbecco's PBS (DPBS; Biological Industries, Kibbutz Beit Ha'emek, Israel), supplemented with $0.01 \%$ glutaraldehyde (Polysciences, Warrington, $\mathrm{PA}, \mathrm{USA})$. The eggs were then washed in a solution of $3 \%$ fetal calf serum (Biological Industries) in DPBS solution, which served as a blocking solution. Zonae pellucida (ZP) were removed using $0.25 \%$ Pronase (Sigma). Zonae pellucida-free eggs were permeabilized for 
10 min in $0.05 \%$ Nonidet P-40 (NP-40; Sigma) in blocking solution and washed in $0.005 \%$ NP-40 in blocking solution. Permeabilized eggs were incubated for $2 \mathrm{~h}$ in the presence of a primary antibody, and washed before transfer to the fluorescently labeled secondary antibody (30 min in the dark).

\section{Calpain labeling}

Monoclonal anti-( $\mu$ calpain) or anti-(m calpain) antibody (1:50 in blocking solution; Calbiochem) served as the primary antibody. Fluorescently labeled donkey anti-mouse IgG Cy3 served as a secondary antibody (1:250; Jackson Immunoresearch Laboratories, West Grove, PA, USA).

\section{Assessment of $C R$}

Cortical granule exudate was detected by labeling fixed eggs with lens culinaris aectin-biotin (Vector Laboratories, Burlingame, CA, USA; $5 \mu \mathrm{g} / \mathrm{ml}$ in DPBS supplemented with $1 \% \mathrm{BSA}$ ), which interacts with cortical granule content (Ducibella et al. 1988). The eggs were then washed and stained with Texas Red-streptavidin (Vector Laboratories; $1 \mu \mathrm{g} / \mathrm{ml}$ in DPBS supplemented with $1 \%$ BSA).

\section{Assessment of the meiotic stage}

The DNA-specific fluorochrome Hoechst $33342(1 \mu \mathrm{g} / \mathrm{ml}$; Sigma), which served to mark the chromatin stage, was added either to the secondary antibody solution while performing calpain labeling or to the Texas Red solution while assessing CR. Resumption of meiosis was documented by monitoring the separation of the chromosomal dyads and the polar body II (PBII) extrusion.

\section{Confocal microscopy}

DNA for calpains $\mu$ and $m$ and cortical granule exudates were visualized and photographed by a Zeiss (Oberkochen, Germany) confocal laser-scanning microscope (LSM). The Zeiss LSM 410 is equipped with a $25 \mathrm{~mW}$ krypton/argon laser, a $10 \mathrm{~mW}$ helium/neon laser (488, 543 and 633 maximum lines) and an UV laser (Coherent Laser Group, Santa Clara, CA, USA). A $40 \times$ numerical aperture/1.2 planapochromat water-immersion lens (Axiovert $135 \mathrm{M}$; Zeiss) was used for all imaging. The eggs were scanned using the LSM through the $z$-axis to perform a section at the equatorial plane of the egg for localization and possible translocation of each calpain. Each experiment was repeated at least three times and at least 20 eggs were examined in each experimental group, of which three or four were analyzed densitometrically. The labeling intensity was measured using the corrected mean density values obtained by the LSM software. The fluorescence intensity was expressed relative to values obtained for MII eggs, which were set to 1.0 (arbitrary units). Calpain translocation was evaluated by calculating the ratio between calpain staining at the egg membrane and in the cytosol.

\section{Immunoblotting}

\section{Calpains}

Samples of 300 cumulus-free MII eggs were collected in $7-10 \mu \mathrm{l}$ TH medium mixed with $7 \mu$ l lysis buffer $(50 \mathrm{mM}$ Tris, $\mathrm{pH} 7.4,1 \% \mathrm{NP}-40,150 \mathrm{mM} \mathrm{NaCl}, 2 \mathrm{mM}$ EDTA, $1 \mathrm{mM} \mathrm{Na}_{3} \mathrm{VO}_{4}, 5 \mathrm{mM} \mathrm{NaF}$ and $10 \mu \mathrm{g} / \mathrm{ml}$ aprotinin (Sigma)). The protein extracts were kept at $-70^{\circ} \mathrm{C}$ until use. Lysates of oocytes were mixed with Laemmli buffer (New England Biolabs, Beverly, MA, USA) and boiled for 5 min. Proteins were separated by SDS/PAGE on $10 \%$ gels at a constant current of $30 \mathrm{~mA}$ alongside marker proteins of known molecular masses (Amersham Bioscience). The gels were electro-transferred onto a nitrocellulose membrane (Amersham Bioscience) for $18 \mathrm{~h}$ at $40 \mathrm{~mA}$. Following electro-transfer, the blots were blocked in 5\% nonfat dry milk in TBS/Tween $(150 \mathrm{mM} \mathrm{NaCl}, 10 \mathrm{mM}$ Tris and $0.5 \%$ Tween 20 ) for $2 \mathrm{~h}$ at room temperature and incubated overnight at $4{ }^{\circ} \mathrm{C}$ with either monoclonal anti-( $\mu$ calpain) (1:100) or anti-(m calpain) (1:150) antibody in blocking solution. The secondary antibody used was donkey anti-mouse antibody (IgG) conjugated to horseradish peroxidase (1:5000). The blots were processed by the chemiluminescence detection system (Supersignal; Pierce, Rockford, IL, USA) and autoradiographed.

\section{Calpain-specific $\alpha$-spectrin-breakdown products}

Samples of either 300 MII eggs or 300 ionomycin-activated eggs were collected as described above, but egg lysates were separated on a 7.5\% gel and then electrotransferred onto a PVDF membrane (Millipore, Bedford, MA, USA). Following $2 \mathrm{~h}$ of blocking ( $5 \%$ nonfat dry milk in TBS/Tween), the membranes were incubated overnight with anti-( $\alpha$-spectrin) monoclonal antibody (AFFINITI Research Products, Exeter, UK; 1:4000). The secondary antibody used was goat anti-mouse antibody (IgG) conjugated to horseradish peroxidase (Jackson Immunoresearch Laboratories; 1:10000). The blots were processed as described for calpains.

\section{Inhibition of calpain activity by calpain synthetic inhibitors}

\section{Parthenogenetic activation}

The eggs were incubated in $\mathrm{TH}$ medium containing $0.4 \%$ BSA for $30 \mathrm{~min}$ in the presence of either calpeptin (Calbiochem; 25-125 $\mu \mathrm{M}$ ) or calpain inhibitor III (MDL28170; Calbiochem; $25-50 \mu \mathrm{M}$ ) as employed to successfully inhibit calpain in other studies (Forsythe and Befus 2003, London 2003, Spira et al. 2003). They were then exposed to parthenogenetic activation by ionomycin, followed by $22 \mathrm{~min}$ of incubation at $37^{\circ} \mathrm{C}$ in the presence of the inhibitor. The eggs were then fixed and labeled for calpain 
isoforms, cortical granule exudate and chromatin, and visualized as described in the section on immunofluorescence, above. Both inhibitors were dissolved in 100\% DMSO, which also served as a control. MIl eggs that had been exposed to either calpain inhibitor without any activation were also assessed, to detect any effect of the inhibitor itself on the egg. The effect of calpain inhibitors on egg activation was explored by evaluating chromatin status as a marker for resumption of meiosis and the degree of CR, both analyzed by immunofluorescence confocal microscopy. For CR assessment, eggs were classified in one of three groups - no CR, weak CR or strong CR based on their fluorescence intensity. The labeling intensity was measured using the corrected mean density values obtained by the LSM software.

\section{In vitro fertilization}

Sperm were collected from the uteri of superovulated rats soon after mating and diluted in modified rat fertilization medium (Shalgi 1991) to a final concentration of $(7-10) \times$ $10^{5}$ spermatozoa $/ \mathrm{ml}$. Aliquots of the sperm suspension $(100 \mu \mathrm{l})$ were incubated for $5 \mathrm{~h}$ in Petri dishes (Corning, Corning Acton, MA, USA) under mineral oil (Sigma) at $37^{\circ} \mathrm{C}, 95 \%$ humidity and $5 \% \mathrm{CO}_{2}$ in air to allow capacitation. MII eggs were collected as described above. The eggs were exposed to $125 \mu \mathrm{M}$ calpeptin $30 \mathrm{~min}$ before they were introduced into the sperm suspension (20 eggs per $100 \mu \mathrm{l}$ capacitated sperm). Eggs exposed to DMSO alone served as a control. The eggs were examined $2 \mathrm{~h}$ later by Nomarski interference-contrast microscopy to determine fertilization. Only eggs containing a sperm tail in the vitellus were classified as fertilized.

\section{Data analysis}

For analyzing the inhibition effect on resumption of meiosis, data were expressed as the fraction of treated eggs successfully reaching each developmental stage divided by the fraction of control eggs reaching the same developmental stage at each time point. The data were evaluated by analysis of variance (ANOVA) to determine whether differences between treated eggs and control eggs were significant. The significance of differences between experimental groups was determined by ANOVA with repeated measures (for calpain inhibitor III, since two concentrations of the inhibitor were compared) or paired $t$-test (for calpeptin, since three concentrations of the inhibitor were compared); $P<0.01$ was considered significant.

For evaluating calpain translocation, ratios of calpain staining at the egg membrane and the cytosol were compared by ANOVA test. The inhibition effect on CR was presented as the number of eggs displaying strong versus weak CR. For each CR pattern, either strong or weak, data were calculated as the ratio between the intensity of the cortical granule exudates and the cortical area of the egg.
Student's $t$-test was applied to compare data; $P<0.01$ was considered significant.

\section{Results}

\section{Detection of calpain isoforms in the rat egg}

Western-blot analysis was performed on extracts of 300 rat eggs arrested at the metaphase of the second meiosis. Using two monoclonal antibodies for either $\mu$ or $\mathrm{m}$ calpains, we could demonstrate a single band of $80 \mathrm{kDa}$ for each isoform (Fig. 1), which conforms to the reported molecular masses of $\mu$ or $\mathrm{m}$ calpains in other cells.

\section{Localization of calpain isoforms throughout egg activation}

To determine the localization of calpain isoforms in the egg at different stages of egg activation, we artificially raised the $\left[\mathrm{Ca}^{2+}\right]_{i}$ by ionomycin, thus inducing parthenogenetic activation. We followed the dynamics of calpain activation by performing immunofluorescence confocal microscopy using calpain-isoform-specific antibodies. The eggs were also labeled for chromatin to distinguish the different stages of egg activation: eggs that had been fixed immediately after ionomycin stimulus still had MII configuration whereas eggs fixed 20-25 min after ionomycin stimulus had an anaphase configuration.

$\mathrm{m}$ Calpain was distributed homogenously throughout the ooplasm in the MII unfertilized egg, with a more distinct labeling of the egg membrane-cortex area as well as the meiotic spindle (Fig. 2A-C; mean ratio value, $1.24 \pm 0.14)$. Immediately after exposure of the eggs to ionomycin, a significantly marked accumulation of $\mathrm{m}$ calpain was observed at the membrane area, as was an enhancement of the spindle staining (Fig. 2D-F; mean ratio value, $1.58 \pm 0.29, P<0.01)$. The faded staining of the spindle area at later stages of development (Fig. 2G-I) can be attributed to the disassembly of the spindle

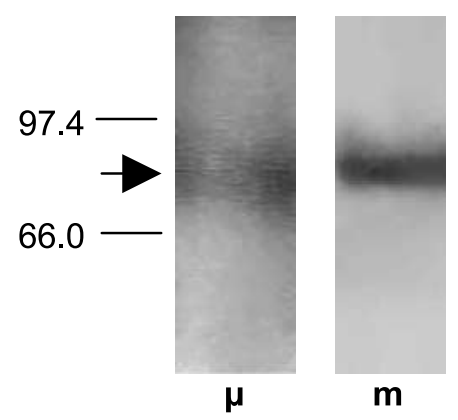

Figure 1 Expression of calpain isoforms in MII rat eggs. Proteins of 300 egg lysates were resolved by SDS/PAGE analysis and transferred onto nitrocellulose paper. Blots were incubated with either anti( $\mu$ calpain) (1:100) or anti-(m calpain) $(1: 150)$ monoclonal antibodies (IgG), followed by secondary goat anti-mouse antibody conjugated to horseradish peroxidase (1:5000) and visualized by enhanced chemiluminescence detection. The arrow points to the calpain bands at $80 \mathrm{kDa}$, as calculated from the migration of known protein standards. 

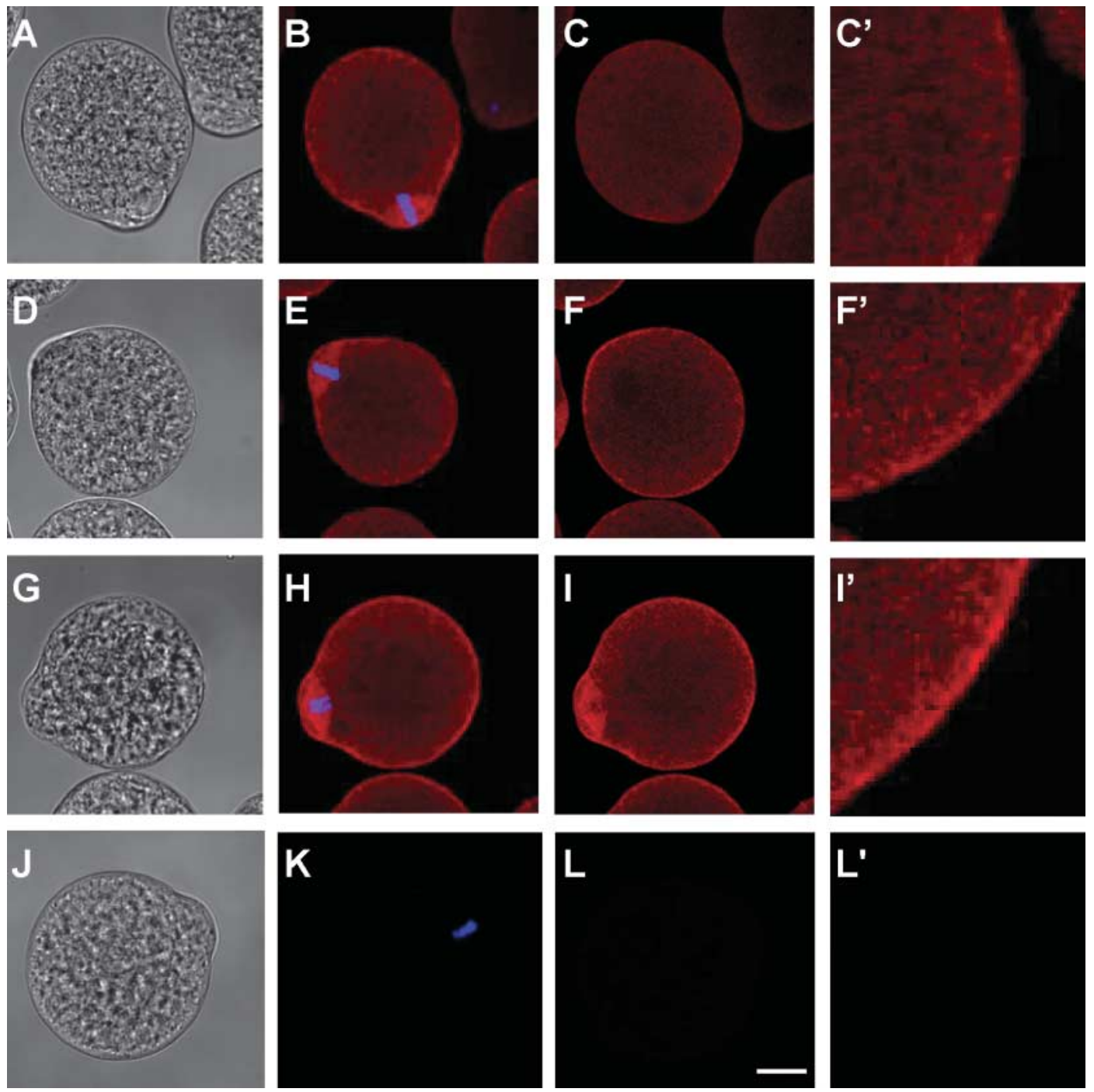

Figure 2 Localization of $\mathrm{m}$ calpain during egg activation. MII eggs (A-C); eggs treated for 3 min with ionomycin, washed and fixed immediately (D-F) or 20 min after activation (G-l; chromosomes at anaphase stage). Primary antibody (anti-(m calpain) (1:50)) was detected by a fluorescently labeled Cy3 secondary antibody (1:250; red). DNA was labeled with Hoechst (blue). Eggs stained only with secondary antibody and Hoechst served as controls $(\mathrm{J}-\mathrm{L})$. At least three independent experiments were performed involving three or four eggs for each group on each experimental day. Cross-sections through the egg meiotic spindle are shown in B, E, H and K. Cross-sections at the equatorial plane of the egg are shown in $\mathrm{C}, \mathrm{F}, \mathrm{I}$ and $\mathrm{L}$. $\mathrm{C}^{\prime}, \mathrm{F}^{\prime}, \mathrm{I}^{\prime}$ and $\mathrm{L}^{\prime}$ depict the cortical area by $\times 4$ magnification. Light microscopy is shown in A, D, G and J. Scale bar, $10 \mu \mathrm{m}$.

structure. To further support the aforementioned findings of calpain translocation to the membrane and the spindle area during egg activation, we followed the localization of $\mathrm{m}$ calpain during in vivo fertilization. Due to the fact that calpain is activated shortly after the first $\left[\mathrm{Ca}^{2+}\right]_{i}$ rise, we examined early stages of fertilization (i.e. before and after sperm binding) according to the stages described previously by Eliyahu \& Sagata \& Watanabe (1989). Eggs at early stages of fertilization were labeled with anti-(m calpain) antibody and Hoechst stain. A relatively uniform distribution with a delicate labeling of the cortex-membrane area was observed throughout the ooplasm of MII-arrested eggs (Fig. 3A-C). m Calpain exhibited marked translocation to the membrane area as well as to the spindle in eggs examined following sperm fusion (Fig. 3D-F). These results correlate to the findings obtained by parthenogenetic activation as described above.

$\mu$ Calpain displayed no remarkable changes in its cellular localization following egg activation (Fig. 4). It was distributed homogenously throughout the cytosol in MII eggs, with distinct staining of the membrane and the spindle without any significant change during or after egg activation.

\section{Calpain activation throughout egg activation}

Calpain-mediated cleavage of the cytoskeletal protein nonerythroid $\alpha$-spectrin (fodrin), which results in a set of 

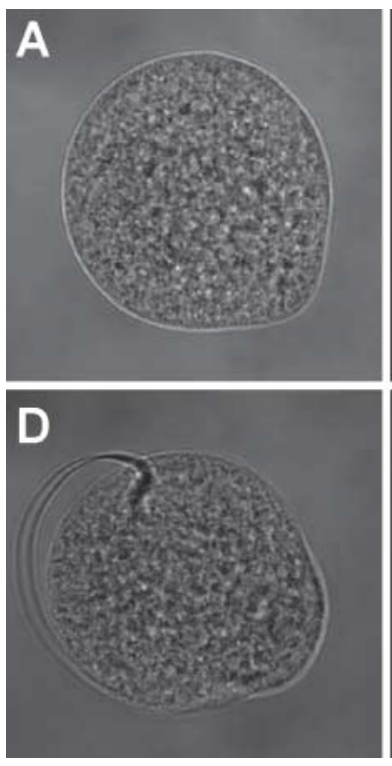
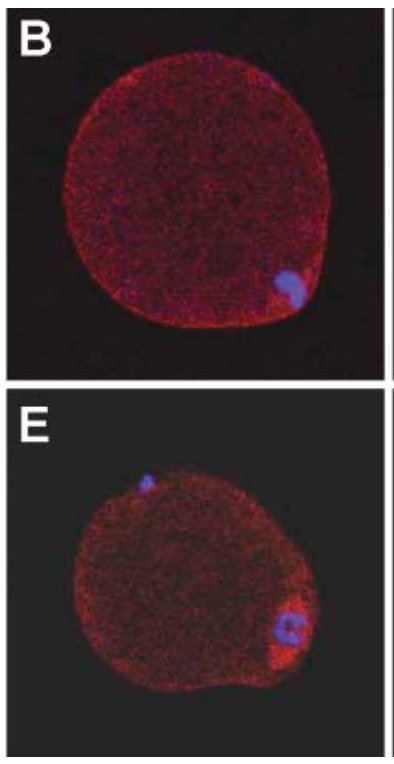
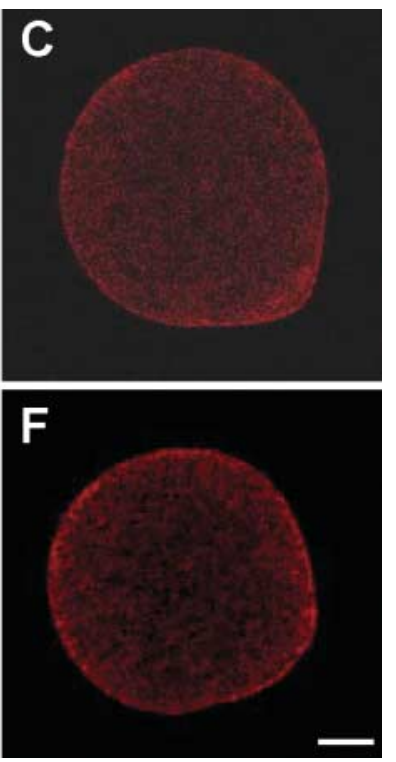

Figure 3 Localization of $m$ calpain during fertilization. MII $(\mathrm{A}-\mathrm{C})$ and in vivo-fertilized $(D-F)$ eggs were stained with anti- $(m$ calpain) antibody (1:50) and Cy3 secondary antibody (1:250). m Calpain (red) was visualized by confocal laser-scanning microscopy. DNA was labeled by Hoechst (blue). Localization of $\mathrm{m}$ calpain during the sperm-fusion phase is seen in $E$ and F. Cross-sections through the egg's meiotic spindle are shown in B and E. Cross-sections at the equatorial plane of the egg are shown in $\mathrm{C}$ and $\mathrm{F}$. Light microscopy is shown in A and D. At least three independent experiments were performed involving three eggs for each group on each experimental day. Scale bar, $15 \mu \mathrm{m}$. large breakdown products, serves as a marker for calpain activation. $\alpha$-Spectrin hydrolysis was determined by immunoblotting extracts of MII eggs and parthenogenetically activated eggs by means of a monoclonal antibody which recognizes the two calpain-mediated breakdown products of 145 and $150 \mathrm{kDa}$. As depicted in Fig. 5, no breakdown products were found in the lysates of MII eggs, whereas both 145 and $150 \mathrm{kDa}$ breakdown products were detected, representing calpain activity, in the lysates of eggs activated by ionomycin.

\section{The role of calpain during egg activation}

To examine the role of calpain during egg activation, the percentage of eggs undergoing resumption of meiosis
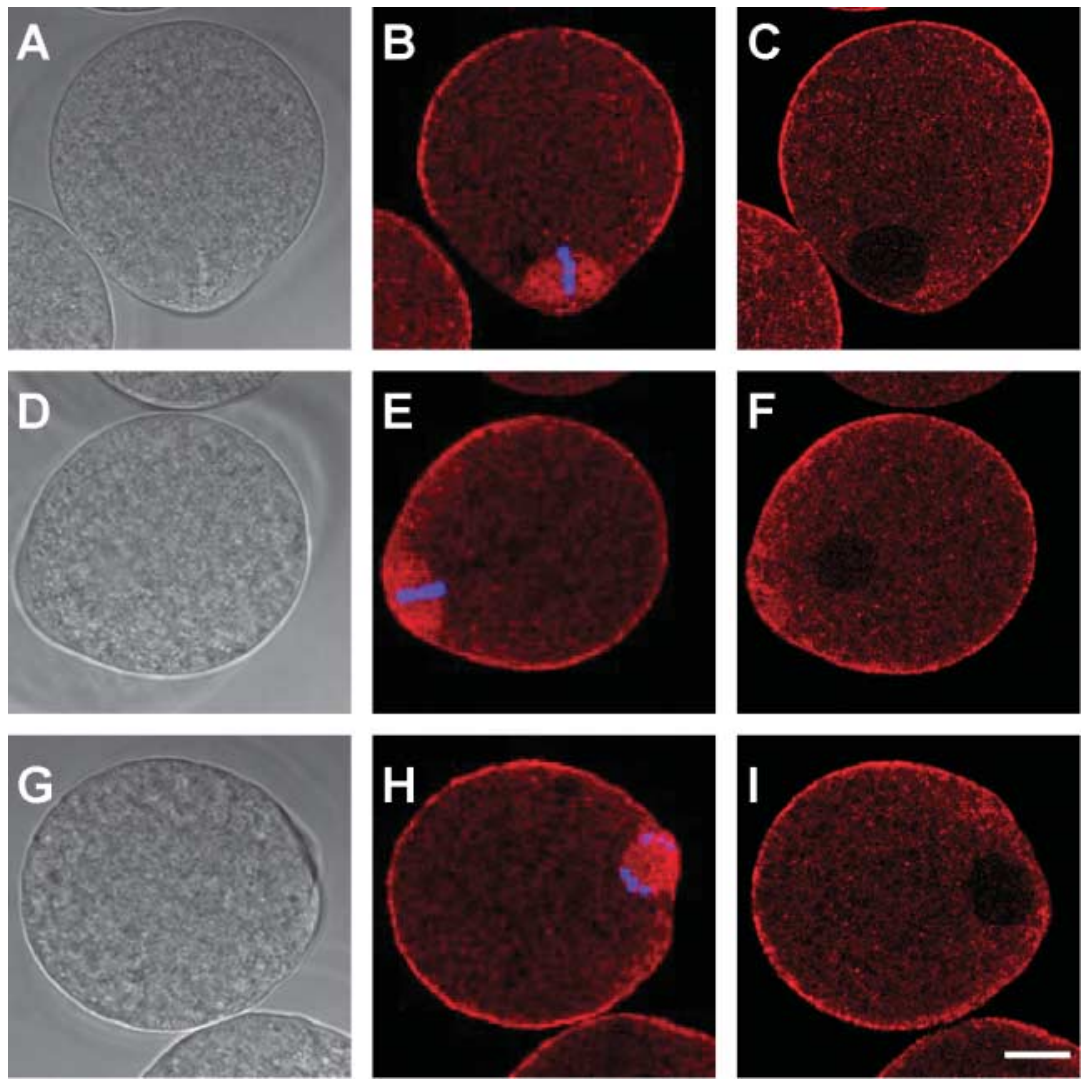

Figure 4 Localization of $\mu$ calpain during egg activation. Mll eggs (A-C). Eggs treated for $3 \mathrm{~min}$ with ionomycin, washed and fixed immediately (D-F) or 20 min after activation (G-l; chromosomes at the anaphase stage). Primary antibody (anti-( $\mu$ calpain) (1:50)) was detected by a fluorescently labeled Cy3 secondary antibody (1:250; red). DNA was labeled with Hoechst (blue). At least three independent experiments were performed involving three or four eggs for each group on each experimental day. Cross-sections through the egg meiotic spindle are shown in B, $\mathrm{E}$ and $\mathrm{H}$. Cross-sections at the equatorial plane of the egg are shown in C, F and I. Light microscopy is shown in A, D and G. Scale bar, $15 \mu \mathrm{m}$. 


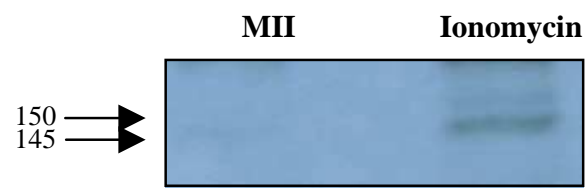

Figure 5 Detection of $\alpha$-spectrin-breakdown products in activated eggs. $300 \mathrm{MII}$ eggs were incubated with ionomycin for $3 \mathrm{~min}$, washed and further incubated for $7 \mathrm{~min}$ in TH medium. Treated eggs were lysed, and proteins were resolved by $7.5 \%$ SDS/PAGE and transferred onto a PVDF membrane. 300 MII-arrested eggs served as controls. Blots were incubated with anti- $\alpha$-spectrin (fodrin) antibody (1:4000), followed by goat anti-mouse horseradish peroxidae (1:20000) and enhanced chemiluminescence detection. The arrows point to the 145 and $150 \mathrm{kDa}$ breakdown products, which are known as $\alpha$-spectrin (fodrin)-breakdown products cleaved by calpain.

and/or cortical granule exocytosis were examined after parthenogenetic activation had been induced in the presence of one of two calpain-selective permeable inhibitors - calpeptin or calpain inhibitor III.

Both resumption of meiosis and CR were affected by each calpain inhibitor (Figs 6 and 7) with a dose-dependent inhibition response. The inhibitory effect of calpeptin was evident with all concentrations tested (Fig. 6A and B). At a concentration of $25 \mu \mathrm{M}$ calpeptin, $56.8 \%$ of eggs resumed meiosis, a value that was significantly lower than the $79.8 \%$ of control eggs lacking the inhibitor $(P<0.01)$. Higher concentrations of the inhibitor (i.e. 75 and $125 \mu \mathrm{M}$ ) yielded a more pronounced inhibition (only 29.3 and $14.0 \%$ of eggs resumed meiosis, respectively, $P<0.01$; paired $t$-test; Fig. 6A). Whereas $51.4 \%$ resumed meiosis with calpain inhibitor III at $25 \mu \mathrm{M}$, only $28.6 \%$ underwent resumption of meiosis with calpain inhibitor III at $50 \mu \mathrm{M}$ $(P<0.01$; ANOVA; Fig. 7A).

When parthenogenetic activation was induced in the presence of calpeptin, the magnitude of $C R$ was also affected. All activated eggs, in both the control group (ionomycin only) and in the presence of any of the calpain inhibitors, displayed CR. However, activated eggs displayed two degrees of cortical granule exudates, classified as weak or strong labeling and assessed using the LSM software (Fig. 6C). Eggs that had been stained strongly attained a mean density value of $180.88 \pm 15.44$ units whereas weakly stained eggs were scored with $44.84 \pm 4.8$ units $(P<0.01)$. Exposure to calpeptin reduced the rate of eggs with strong CR to $84.52 \%$ at $75 \mu \mathrm{M}$ and $48.3 \%$ at $125 \mu \mathrm{M}$, as compared with controls (Fig. 6B). When we examined the effect of calpain inhibition in ionomycin- versus puromycin-activated eggs, resumption of meiosis was impeded in both sets (Fig. 6A and D). Calpain inhibitor III was also effective in reducing the CR extent but only at its higher concentration (Fig. 7B).

To exclude a possible effect of the inhibitors per se on MII eggs, they were incubated with the higher concentration of each inhibitor devoid of any activation stimulus.
No change in the meiotic status, in the CR or in localization of calpain isoforms could be detected.

\section{Effects of calpeptin on fertilization}

For the in vitro fertilization assay, eggs were incubated in TH medium alone (control) or in the presence of calpeptin, transferred into sperm suspension in the presence of the inhibitor for in vitro fertilization and assessed for fertilization as described in the Materials and Methods section. In three separate experiments, the majority of control eggs were fertilized in vitro (sperm penetrated and PBII emitted in $75.0 \pm 7.3 \%$ of the 110 eggs). Of the 128 eggs incubated in the presence of $125 \mu \mathrm{M}$ calpeptin, only $24.6 \pm 11.9 \%$ were fertilized (i.e. PBII emitted; Fig. 6E).

\section{Discussion}

The earliest event observed following sperm-egg interaction in all mammalian eggs is an abrupt rise in $\left[\mathrm{Ca}^{2+}\right]_{\text {i }}$. This study was designed initially to investigate the calpain system in mammalian eggs as part of the search for the downstream factors activated by this calcium rise within the egg at fertilization. The calpain system was chosen based on the published data and as a continuation of our previous study, which demonstrated calpain expression in the rat egg (Malcov et al. 1997). In our current work, the expression of ubiquitous calpain isoforms in the rat egg as well as calpain function were studied during parthenogenetic activation and at fertilization using two specific calpain inhibitors. Calpain involvement during resumption of meiosis and during cortical granule exocytosis has been demonstrated, apparently via cytoskeleton remodeling. Calpains represent a well-conserved family of cysteine proteases activated by calcium. Two ubiquitous calpains, $\mu$ and $\mathrm{m}$, were named according to their relative requirement for calcium concentrations in vitro, micromolar and millimolar respectively, to elicit proteolytic activity (Croall \& DeMartino 1991). At fertilization, $\left[\mathrm{Ca}^{2+}\right]_{i}$ ascends to about $10^{-6} \mathrm{M}$. Since calpain requires supraphysiological $\mathrm{Ca}^{2+}$ levels in vitro, several alternative or complementary mechanisms of activation and regulation have been suggested to explain the lower $\mathrm{Ca}^{2+}$ requirements in physiological conditions. Among those are: binding of calpain to membrane phospholipids, autolysis, escape from its endogenous inhibitor calpastatin, binding of coactivators and calpain phosphorylation (Michetti et al. 1991, Kuo et al. 1994, Arthur \& Carafoli, 1996, Melloni et al. 1998, Suzuki \& Sorimachi 1998, Barnoy et al. 1999, Tullio et al. 1999, Glading et al. 2002). Calpains have been defined as biomodulators since calpain-mediated proteolysis often modulates its substrate activity by releasing a co-factor.

The role of calpain at fertilization has been studied in a few species. It was implied that calpain may participate in the regulation of meiosis at fertilization in Xenopus laevis eggs (Watanabe et al. 1989). Injection of calpain into the 

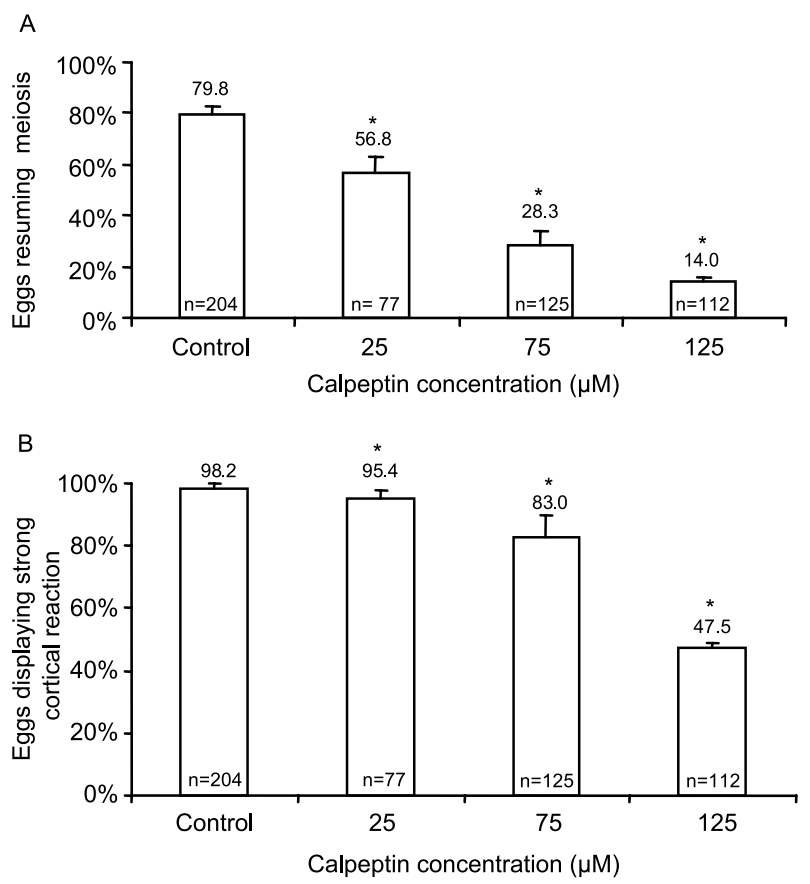

C
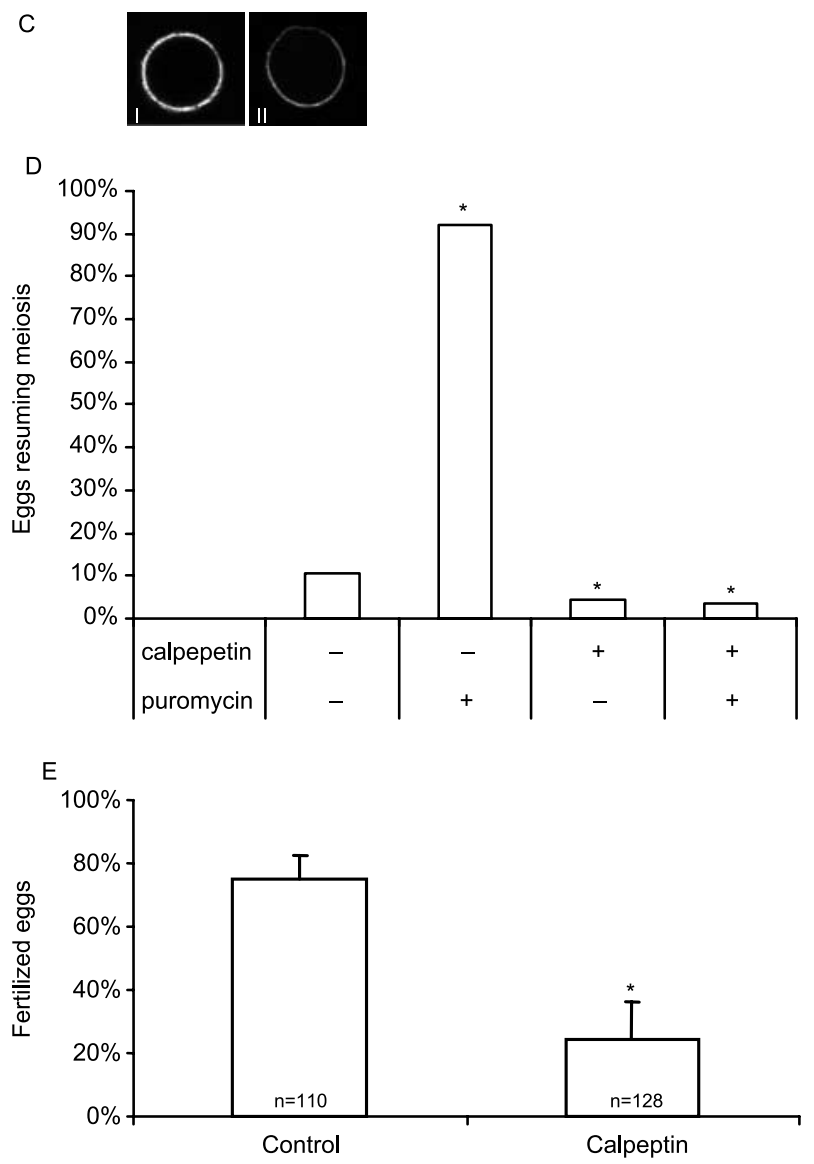

Figure 6 Inhibition of calpain by calpeptin. (A and B) MII eggs were incubated for $30 \mathrm{~min}$ in the presence of calpeptin or DMSO (control), activated by $2 \mu \mathrm{M}$ ionomycin for $3 \mathrm{~min}$ and further incubated in the presence of the inhibitor for $22 \mathrm{~min}$. The eggs were then fixed and labeled for cortical granule content, as described in the text. The chromatin stage was evaluated by Heochst labeling (* Student $t$-test nuclei of prophase-arrested starfish oocytes induced resumption of meiosis, probably by proteolysis of cytoskeletal proteins during the disassembly of the nuclear envelope (Santella et al. 2000). We have previously demonstrated calpain expression during rat egg activation (Malcov et al. 1997). In the present study, we focused on calpain ubiquitous isoforms, $\mu$ and $\mathrm{m}$, in terms of their localization, activation and possible role during egg activation. We demonstrated the expression of both isoforms in the rat egg as $80 \mathrm{kDa}$ proteins, similar to what had been reported in somatic cells. Immunofluorescence combined with confocal microscopy depicted a relatively homogenous distribution of $\mathrm{m}$ calpain in the cytoplasm of MII eggs, with a subtle marking of the membrane-cortex area and the meiotic spindle apparatus. Shortly after increasing the $\left[\mathrm{Ca}^{2+}\right]_{i}$ by either ionophore (Raz \& Shalgi 1998) or at the actual physiological process of fertilization, a marked accumulation of $\mathrm{m}$ calpain was observed at the membrane and at the spindle area. Similar results of calpain localization were observed during the mitotic division (Schollmeyer 1988, Lane et al. 1992).

On the other hand, $\mu$ calpain did not show any significant change in its localization during egg activation. We may therefore speculate that $\mu$ calpain does not play an active role during this process but rather functions as a bystander or a backup system for $m$ calpain. As a housekeeping gene product, $\mu$ calpain is expressed within the egg. It is quiescent during the early phase of fertilization, but may participate later during early cleavages.

The cytoskeletal protein $\alpha$-spectrin (fodrin) is regulated by calpain-mediated cleavage to produce a set of large breakdown products. We herein displayed $\alpha$-spectrin degradation during parthenogenetic egg activation using a calpain-specific $\alpha$-spectrin-breakdown products antibody. $\alpha$-Spectrin has been detected previously in the cortical area of mouse eggs (Bonder et al. 1989, Bonder \& Fishkind 1995) and adjacent to the meiotic spindle (Schatten et al. 1986). Correspondingly, both calpain isoforms appeared to be localized to the same area. Taken together, according to known features of calpain activation, both translocation of $\mathrm{m}$ calpain and the presence of breakdown products may indicate a correlation between mammalian egg activation and calpain activation.

To examine the role of calpain during egg activation, resumption of meiosis and cortical granule exocytosis were examined following parthenogenetic activation in the presence of calpain inhibitors. Both calpeptin and calpain inhibitor III dose-dependently impeded resumption of

$P<0.01$ ). (C) Assessment of the CR. Labeling of cortical granule exudates was classified as strong (I) or weak (II). (D) MII eggs were incubated for $30 \mathrm{~min}$ in either $125 \mu \mathrm{M}$ calpeptin or control medium. Eggs from each of the two groups were then incubated for another $3 \mathrm{~h}$ with or without $20 \mu \mathrm{M}$ puromycin. (E) In vitro fertilization of eggs that had been incubated in the presence of $125 \mu \mathrm{M}$ calpeptin $30 \mathrm{~min}$ prior to introduction to sperm suspension. Eggs containing a sperm tail in the vitellus were classified as fertilized. 

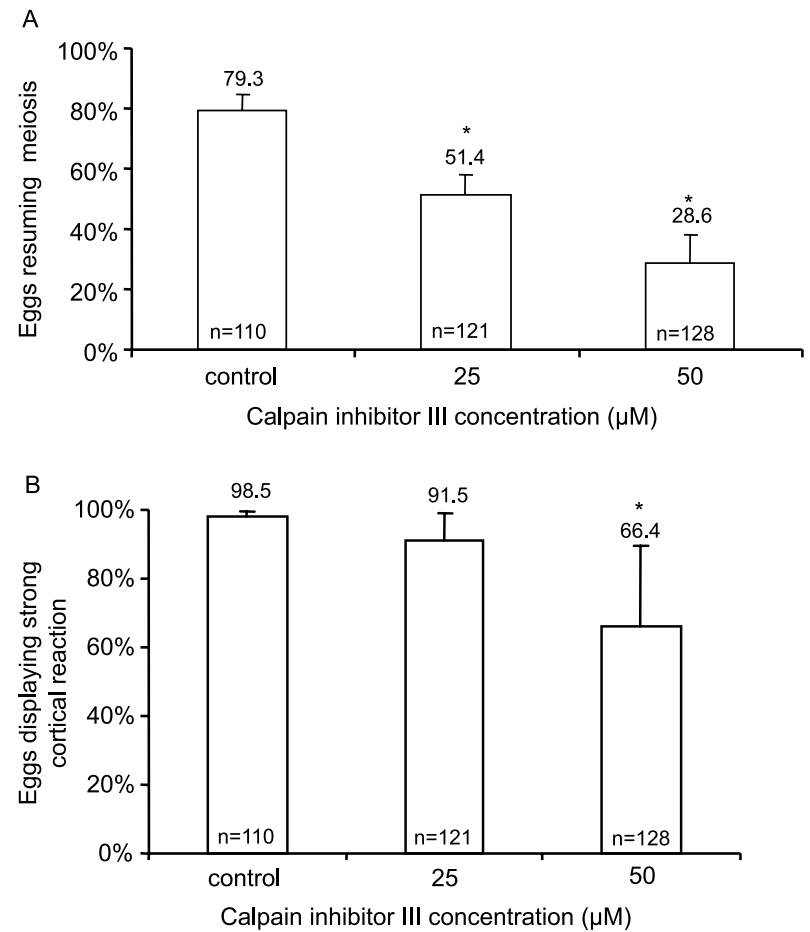

Figure 7 Inhibition of calpain by calpain inhibitor III. MII eggs were incubated for $30 \mathrm{~min}$ in the presence of calpain inhibitor III or DMSO (control), activated by $2 \mu \mathrm{M}$ ionomycin for $3 \mathrm{~min}$ and further incubated in the presence of the inhibitor for $22 \mathrm{~min}$. The eggs were then fixed and labeled for cortical granule content, as described in the text. The chromatin stage was evaluated by Heochst labeling (* ANOVA with repeated measures $P<0.01$ ).

the meiosis induced by ionomycin. The chromosomes of the activated eggs in the presence of the inhibitor were aligned accurately as they were in MIl-arrested eggs (the control). Lower concentrations of the inhibitor resulted in a minimal separation of the chromatids. The chromatid segregation is induced by a process named biorientation. Thus, the pole-ward movement of the kinetochore in the metaphase-anaphase transition is driven by disassembly of microtubules, and by the function of mechanochemical motor proteins, such as dynein and kinesin, on the one hand and the anaphase-promoting complex/cyclosome (APC/C) on the other (Wittmann et al. 2001, Terret et al. 2003). Microtubule dynamics seem to be regulated mainly by microtubule-associated proteins, which are known as favorable calpain substrates (Fischer et al. 1991, Johnson \& Foley 1993, Alexa et al. 1996). Calpain was shown to mediate disassembly of the microtubule lattice as well (Billger et al. 1988, Pettigrew et al. 1996). Therefore, both microtubule-associated proteins and the microtubules can serve as potential targets for calpain isoforms during resumption of the second meiosis.

Little is known about the cellular pathways by which calcium signals egg activation at fertilization. A role had recently been suggested for proteins, such as CaMKII and calmodulin, in mediating the signal required for the resumption of meiosis (Tatone et al. 2002, Markoulaki et al. 2003). In a study exploring the role of CaMKII during activation of mouse eggs, Markoulaki et al. (2004) demonstrated that CaMKII antagonist inhibits cell-cycle progression in fertilized, but not cycloheximide-treated, eggs. When we examined the effect of calpain inhibition in ionomycin- versus puromycin-activated eggs, resumption of meiosis was impeded in both sets. Cycloheximideinduced activation of mouse eggs, as well as puromycin, was shown to have resulted in a decrease in both cdc2/cyclin B and mitogen-activated protein kinase (MAP kinase) activities (Zernicka-Goetz \& Maro 1993, Moos et al. 1996). Cell-cycle arrest throughout the first and second meiosis is known to depend on MAP kinase activity (Kishimoto 2003, 2004. Furthermore, MAP kinase contributes to the prevention of parthenogenetic activation (Picard et al. 1996). Calpain, which is also a calciumdependent enzyme, has not yet been positioned in the cascade of events leading to egg activation. Investigation of a calpain signal transduction pathway during fibroblast motility, however, revealed that calpain activity is regulated downstream of MAP kinase (Glading et al. 2000). We can therefore contend that inhibition of calpain in puromycin-treated eggs does not differ from its inhibition in ionomycin-treated eggs since the inhibition effect probably occurs downstream in the cascade of events leading to resumption of meiosis. Nevertheless, we cannot exclude that calpeptin may have more than one mode of action. It may inhibit the proteasome as well as calpain activation. On the contrary, the results obtained by Markoulaki et al. (2004) may suggest that CaMKII is involved upstream at the level of cdc2 and cyclin B and thus inhibition of CaMKII in the presence of an activator, such as cycloheximide, varies in its effect in comparison to fertilization- $/ \mathrm{Ca}^{2+}$-induced activation.

Both inhibitors also affected a second feature of egg activation, the $C R$, but to a lesser extent than inhibition of the resumption of meiosis. Thus, calpain may possibly impinge on cytoskeletal elements in the egg cortex. The cortical region in various cells contains numerous components of the cytoskeleton, such as microtubule-associated proteins, actin and $\alpha$-spectrin, which are all known as calpain's substrates in vivo (Carafoli \& Molinari 1998, Potter et al. 1998). These cytoskeleton components have been shown to be localized to the cortical region of the mammalian egg as well (Bonder et al. 1989, Bonder \& Fishkind 1995).

A role has been implied for calpain in membrane fusion in myoblasts (Barnoy et al. 1999), in the transformation of axonal vesicles in regenerating neurons (Spira et al. 2003) and in platelets (Potter et al. 1998, Fox 2001). Thus, calpain might be involved in the cascade of events leading to cytoskeleton remodeling at the egg cortex in order to facilitate fusion of cortical granules. Being a pluripotential protease which participates in diverse cellular processes, calpain's role may be attributed to several facets of the signal transduction that occurs during egg activation at 
fertilization. Our finding in which calpain inhibition hinders resumption of meiosis lends credence to a model in which calpain activation is required for the cytoskeletal elements of the meiotic spindle to allow segregation of chromatids. However, it is important to point out that resumption of meiosis is a complex network of signal transduction events and that a direct correlation between the aforementioned potential substrates and calpain should be explored further.

\section{Acknowledgements}

We are thankful to Dr Leonid Mittelman for his useful assistance with the confocal microscopy, to Dr Nechama Kosower for her valuable professional advice, to Ariela Carmon, Tanya Cohen, Tamar Shwartz and Nava Mei-Raz, embryologists at the Racin IVF laboratory, for their skillful technical assistance and to Ruth Kraicer for her technical support. Esther Eshkol is thanked for editorial assistance. The authors declare that there is no conflict of interest that would prejudice the impartiality of this scientific work.

\section{References}

Alexa A, Tompa P, Baki A, Vereb G \& Friedrich P 1996 Mutual protection of microtubule-associated protein 2 (MAP2) and cyclic AMP-dependent protein kinase II against mu-calpain. Journal of Neuroscience Research 44 438-445.

Arthur JS \& Crawford C 1996 Investigation of the interaction of m-calpain with phospholipids: calpain-phospholipid interactions. Biochimica et Biophysica Acta 1293 201-206.

Barnoy S, Zipser Y, Glaser T, Grimberg Y \& Kosower NS 1999 Association of calpain $\left(\mathrm{Ca}^{2+}{ }^{2+}\right)$-dependent thiol protease) with its endogenous inhibitor calpastatin in myoblasts. Journal of Cellular Biochemistry 74 522-531.

Ben-Yosef D, Oron Y \& Shalgi R 1995 Low temperature and fertilization-induced $\mathrm{Ca}^{2+}$ changes in rat eggs. Molecular Reproduction and Development 42 122-129.

Billger M, Wallin M \& Karlsson JO 1988 Proteolysis of tubulin and microtubule-associated proteins 1 and 2 by calpain I and II. Difference in sensitivity of assembled and disassembled microtubules. Cell Calcium $933-44$.

Billger M, Nilsson E, Karlsson JO \& Wallin M 1993 Calpain processing of brain microtubules from the Atlantic cod, Gadus morhua. Molecular and Cellular Biochemistry 121 85-92.

Bonder EM \& Fishkind DJ 1995 Actin-membrane cytoskeletal dynamics in early sea urchin development. Current Topics in Developmental Biology 31 101-137.

Bonder EM, Fishkind DJ, Cotran NM \& Begg DA 1989 The cortical actin-membrane cytoskeleton of unfertilized sea urchin eggs: analysis of the spatial organization and relationship of filamentous actin, nonfilamentous actin, and egg spectrin. Developmental Biology 134 327-341.

Carafoli E \& Molinari M 1998 Calpain: a protease in search of a function? Biochemical and Biophysical Research Communications 247 193-203.

Croall DE \& DeMartino GN 1991 Calcium-activated neutral protease (calpain) system: structure, function, and regulation. Physiological Reviews 71 813-847.

Ducibella T, Anderson E, Albertini DF, Aalberg J \& Rangarajan S 1988 Quantitative studies of changes in cortical granule number and distribution in the mouse oocyte during meiotic maturation. Developmental Biology 130 184-197.
Ducibella T, Duffy P \& Buetow J 1994 Quantification and localization of cortical granules during oogenesis in the mouse. Biology of Reproduction $\mathbf{5 0}$ 467-473.

Ducibella T, Huneau D, Angelichio E, Xu Z, Schultz RM, Kopf GS, Fissore R, Madoux S \& Ozil JP 2002 Egg-to-embryo transition is driven by differential responses to $\mathrm{Ca}^{2+}$ oscillation number. Developmental Biology 250 280-291.

Eliyahu E \& Shalgi R 2002 A role for protein kinase C during rat egg activation. Biology of Reproduction 67 189-195.

Fischer I, Romano-Clarke G \& Grynspan F 1991 Calpain-mediated proteolysis of microtubule associated proteins MAP1B and MAP2 in developing brain. Neurochemical Research 16 891-898.

Forsythe P \& Befus AD 2003 Inhibition of calpain is a component of nitric oxide-induced down-regulation of human mast cell adhesion. Journal of Immunology 170 287-293.

Fox JE 2001 Cytoskeletal proteins and platelet signaling. Thrombosis and Haemostasis 86 198-213.

Glading A, Chang P, Lauffenburger DA \& Wells A 2000 Epidermal growth factor receptor activation of calpain is required for fibroblast motility and occurs via an ERK/MAP kinase signaling pathway. Journal of Biological Chemistry 275 2390-2398.

Glading A, Lauffenburger DA \& Wells A 2002 Cutting to the chase: calpain proteases in cell motility. Trends in Cell Biology 12 46-54.

Jaffe LF 1983 Sources of calcium in egg activation: a review and hypothesis. Developmental Biology 99 265-276.

Johnson GV \& Foley VG 1993 Calpain-mediated proteolysis of microtubule-associated protein 2 (MAP-2) is inhibited by phosphorylation by cAMP-dependent protein kinase, but not by $\mathrm{Ca}^{2+} /-$ calmodulin-dependent protein kinase II. Journal of Neuroscience Research 34 642-647.

Kishimoto T 2003 Cell-cycle control during meiotic maturation. Current Opinion in Cell Biology 15 654-663.

Kishimoto T 2004 More than G1 or G2 arrest: useful starfish oocyte systemfor investigating skillful MAP kinase. Biology of the Cell 96 $241-244$.

Kline D \& Kline JT 1992 Repetitive calcium transients and the role of calcium in exocytosis and cell cycle activation in the mouse egg. Developmental Biology 149 80-89.

Kuo WN, Ganesan U, Davis DL \& Walbey DL 1994 Regulation of the phosphorylation of calpain II and its inhibitor. Molecular and Cellular Biochemistry 136 157-161.

Lane RD, Allan DM \& Mellgren RL 1992 A comparison of the intracellular distribution of mu-calpain, m-calpain, and calpastatin in proliferating human A431 cells. Experimental Cell Research 203 $5-16$.

Lawrence Y, Whitaker M \& Swann K 1994 Sperm-egg fusion is the prelude to the initial $\mathrm{Ca}^{2+}$ increase at fertilization in the mouse. Development $124233-241$.

London FS 2003 The protein kinase C inhibitor RO318220 potentiates thrombin-stimulated platelet-supported prothrombinase activity. Blood $12472-2481$.

Lorca T, Galas S, Fesquet D, Devault A, Cavadore JC \& Doree M 1991 Degredation of the proto-oncogene product p39mos is not necessary for cyclin proteolysis and exit from meiotic metaphase requirement for a $\mathrm{Ca}^{+2}$-calmodulin dependent event. EMBO Journal 10 2087-2093.

Malcov M, Ben-Yosef D, Glaser T \& Shalgi R 1997 Changes in calpain during meiosis in the rat egg. Molecular Reproduction and Development 48 119-126.

Markoulaki S, Matson S, Abbott AL \& Ducibella T 2003 Oscillatory CaMKII activity in mouse egg activation. Developmental Biology 258 464-474.

Markoulaki S, Matson S \& Ducibella T 2004 Fertilization stimulates long-lasting oscillations of CaMKII activity in mouse eggs. Developmental Biology 272 15-25.

Melloni E, De Tullio R, Averna M, Tedesco I, Salamino F, Sparatore B \& Pontremoli S 1998 Properties of calpastatin forms in rat brain. FEBS Letters 431 55-58. 
Michetti M, Viotti PL, Melloni E \& Pontremoli S 1991 Mechanism of action of the calpain activator protein in rat skeletal muscle. European Journal of Biochemistry 202 1177-1180.

Miyazaki S, Shirakawa H, Nakada K \& Honda Y 1993 Essential role of the inositol 1,4,5-trisphosphate receptor/ $\mathrm{Ca}^{2+}$ release channel in $\mathrm{Ca}^{2+}$ waves and $\mathrm{Ca}^{2+}$ oscillations at fertilization of mammalian eggs. Developmental Biology 158 62-78.

Moos J, Kopf GS \& Schultz RM 1996 Cycloheximide-induced activation of mouse eggs: effects on cdc2/cyclin B and MAP kinase activities. Journal of Cell Science 109 739-748.

Murachi T 1989 Intracellular regulatory system involving calpain and calpastatin. Biochemistry International 18 263-294.

Pettigrew LC, Holtz ML, Craddock SD, Minger SL, Hall N \& Geddes JW 1996 Microtubular proteolysis in focal cerebral ischemia. Journal of Cerebral Blood Flow and Metabolism 16 1189-1202.

Picard A, Galas S, Peaucellier G \& Doree M 1996 Newly assembled cyclin B-cdc2 kinase is required to suppress DNA replication between meiosis I and meiosis II in starfish oocytes. EMBO Journal 15 3590-3598.

Potter DA, Tirnauer JS, Janssen R, Croall DE, Hughes CN, Fiacco KA, Mier JW, Maki M \& Herman IM 1998 Calpain regulates actin remodeling during cell spreading. Journal of Cell Biology 141 647-662.

Raz T \& Shalgi R 1998 Early events in mammalian egg activation. Human Reproduction (Supplement 4) 133-145.

Sagata N, Watanabe N, Vande Woude GF \& Ikawa Y 1989 The Cmos proto-oncogene product is a cytostatic factor responsible for meiotic arrest in vertebrate eggs. Nature 342 12-18.

Santella L, Kyozuka K, De Riso L \& Carafoli E 1998 Calcium, protease action, and the regulation of the cell cycle. Cell Calcium $\mathbf{2 3}$ $123-130$.

Santella L, Kyozuka K, Hoving S, Munchbach M, Quadroni M, Dainese P, Zamparelli C, James P \& Carafoli E 2000 Breakdown of cytoskeletal proteins during meiosis of starfish oocytes and proteolysis induced by calpain. Experimental Cell Research 259 117-126.

Schatten H, Cheney R, Balczon R, Willard M, Cline C, Simerly C \& Schatten G 1986 Localization of fodrin during fertilization and early development of sea urchins and mice. Developmental Biology 118 457-466.

Schollmeyer JE 1988 Calpain II involvement in mitosis. Science 240 911-913.

Shalgi R 1991 Fertilization in the rat. In A Comparative Overview of Mammalian Fertilization, pp 245-255. Eds BS Dunbar \& MG O'Rand. New York: Plenum Press.
Sorimachi H, Tsukahara T, Okada-Ban $M$, Sugita $H$, Ishiura S \& Suzuki K 1995 Identification of a third ubiquitous calpain specieschicken muscle expresses four distinct calpains. Biochimica et Biophysica Acta $1261381-393$.

Spira ME, Oren R, Dormann A \& Gitler D 2003 Critical calpaindependent ultrastructural alterations underlie the transformation of an axonal segment into a growth cone after axotomy of cultured Aplysia neurons. Journal of Comparative Neurology 457 293-312.

Suzuki K \& Sorimachi H 1998 A novel aspect of calpain activation. FEBS Letters 433 1-4.

Tatone C, Monache SD, lorio R, Caserta D, Cola MD \& Colonna R 2002 Possible role for $\mathrm{Ca} 2+$ calmodulin-dependent protein kinase II as an effector of the fertilization $\mathrm{Ca} 2+$ signal in mouse oocyte activation. Molecular Human Reproduction 8 750-757.

Terret ME, Wassmann K, Waizenegger I, Maro B, Peters JM \& Verlhac MH 2003 The meiosis I-to-meiosis II transition in mouse oocytes requires separase activity. Current Biology 13 1797-1802.

Tombes RM, Simerly C, Borisy GG \& Schatten G 1992 Meiosis, egg activation, and nuclear envelope breakdown are differentially reliant on $\mathrm{Ca}^{2+}$, whereas germinal vesicle breakdown is $\mathrm{Ca}^{2+}$ independent in the mouse oocyte. Journal of Cell Biology 117 799-811.

Tullio RD, Passalacqua M, Averna M, Salamino F, Melloni E \& Pontremoli S 1999 Changes in intracellular localization of calpastatin during calpain activation. Biochemical Journal 343 467-472.

Vincent C, Cheek TR \& Johnson MH 1992 Cell cycle progression of parthenogenetically activated mouse oocytes to interphase is dependent on the level of internal calcium. Journal of Cell Science 103 389-396.

Watanabe N, Vande Woude GF, Ikawa Y \& Sagata N 1989 Specific proteolysis of the c-mos proto-oncogene product by calpain on fertilization of Xenopus eggs. Nature 342 505-511.

Wittmann T, Hyman A \& Desai A 2001 The spindle: a dynamic assembly of microtubules and motors. Nature Cell Biology 3 28-34.

Zernicka-Goetz M \& Maro B 1993 Oxadaic acid affects spindle organization in metaphase II-arrested rat oocytes. Experimental Cell Research 207 189-193.

Received 13 December 2004

First decision 7 January 2005

Revised manuscript received 8 March 2005

Accepted 24 May 2005 